\title{
Trajetória histórica do licenciamento ambiental da Hidrelétrica Santo Antônio do Jari/Amapá-Brasil
}

\author{
Historical trajectory of environmental licensing of \\ Santo Antônio do Jari Hydroelectric/Amapá-Brazil
}

\section{Maíria de Sousa Lopes ${ }^{1}$ \\ Daguinete Maria Chaves Brito²}

\begin{abstract}
1 Mestre em Ciências Ambientais. Universidade Federal do Amapá. E-mail: mairia_lopes@hotmail.com
2 Doutora e Docente do Curso de Geografia, Universidade Federal do Amapá. E-mail: dagnete@uol.com.br
\end{abstract}

RESUMO: Este estudo teve o objetivo de avaliar a trajetória histórica do licenciamento ambiental da Usina Hidrelétrica Santo Antônio do Jari, construída no rio Jari, limite dos estados de Amapá e Pará. Metodologicamente utilizou-se pesquisa bibliográfica e de documentos dos órgãos oficiais responsáveis pelas análises e aprovação das licenças. Os resultados principais indicam que o processo de licenciamento da hidrelétrica ocorreu de modo conflitoso e com grandes prejuízos socioambientais, principalmente, para as comunidades afetadas pela construção da Hidrelétrica, portanto, conclui-se que o processo de licenciamento não seguiu aos tramites previstos pela legislação brasileira.

Palavras-chaves: UHE Santo Antônio do Jari. Licenciamento Ambiental. Impactos ambientais. Avaliação de Impacto Ambiental.

ABSTRACT: This study aimed to evaluate the historical trajectory of the environmental licensing of the Santo Antônio do Jari Hydroelectric Power Plant, built on the Jari River, boundary of the states of Amapá and Pará. Methodologically, a bibliographic and documentary search was used. review and approval of licenses. The main results indicate that the licensing process of the dam occurred in a conflicting way and with great social and environmental damages, especially for the communities affected by the construction of the Dam, therefore, it is concluded that the licensing process did not follow the procedures provided for by the Brazilian legislation. .

Keywords: Santo Antônio do Jari HPP. Environmental Licensing. Environmental impacts. Environmental Impact Assessment.

Sumário: Introdução - 1 Impactos Decorrentes da Implantação de UHE - 2 As UHE Na Amazônia - 3 Histórico da UHE Santo Antônio do Jari - 4 Estudos Ambientais do Licenciamento - 5 Impactos Socioambientais da UHE Santo Antônio do Jari - Considerações Finais - Referências

\section{INTRODUÇÃO}

A economia do Brasil depende do aproveitamento adequado do potencial de geração de energia elétrica para sustentar o seu crescimento. Considerando isso, pode-se afirmar que o setor elétrico brasileiro tem significativa responsabilidade no desenvolvimento do país. Dada a crescente demanda por energia elétrica, o país teve a necessidade de ampliar seu parque gerador, culminando na estruturação de uma matriz energética baseada na edificação de grandes Usinas Hidrelétricas (UHE), em função do seu amplo potencial hidrelétrico. 
Esse potencial é estimado em $260 \mathrm{GW}$, dos quais aproximadamente 43\% estão localizados na região Norte do país (FACURI, 2004; MME, 2007, MORET'TO et al., 2012). A instalação de UHE pode interferir positiva ou negativamente na dinâmica local gerando conflitos socioambientais, resultantes das diferentes formas de uso dos recursos naturais e do espaço geográfico e, significativos impactos sobre o meio ambiente devendo, portanto, passar por um processo de licenciamento ambiental para identificar os impactos diretos e indiretos sobre a região de influência da barragem (PIAGENTINI, BENASSI e PENTEADO, 2014).

A legislação brasileira que instituiu a Política Nacional do Meio Ambiente (Lei no 6.938/1981) tem como objetivo compatibilizar o desenvolvimento socioeconômico com a conservação do meio ambiente. Nela a Avaliação de Impacto Ambiental (AIA) e o licenciamento ambiental são elencados como instrumentos da política ambiental, criados para auxiliá-la no alcance de seus objetivos.

Para tal, ela prevê que para a construção de qualquer projeto com potencial causador de degradação ambiental, é necessária a realização da AIA (BRASIL, Lei no 6.938/1981). Sumarizando, a AIA é um instrumento inicial que fornece subsídios para estudos mais aprofundados e à tomada de decisão quanto a viabilidade socioambiental de instalação de determinado empreendimento.

Outro importante marco da legislação ambiental brasileira é a Resolução do Conselho Nacional do Meio Ambiente (CONAMA) no 01/1986, que determina as diretrizes gerais para a realização da AIA. Em seu escopo são elencados número significativo de atividades modificadoras do meio ambiente, que deverão elaborar Estudo de Impacto Ambiental (EIA) e seu respectivo Relatório de Impacto Ambiental (RIMA) anteriormente à realização do licenciamento ambiental de suas atividades, entre eles estão as obras hidráulicas para a exploração dos recursos hídricos. A partir de sua publicação, o licenciamento passou a ser precedido de EIA e de RIMA sempre que a obra ou atividade possa causar significativo impacto ambiental.

O licenciamento ambiental tem como objetivo regular as atividades e empreendimentos que utilizam os recursos naturais e podem causar degradação ambiental, visando a proteção do meio ambiente, agindo de maneira preventiva e corretiva sob os possíveis impactos decorrentes das atividades (TCU, 2007). O Decreto Federal no 99.274/1990, auxiliado pela Resolução CONAMA n 237/1997, estabelece que cada etapa do licenciamento requer a licença adequada, conforme expresso pelo Banco Mundial (2008) e Santos (2015):

1) Licença Prévia (LP), concedida na fase preliminar do planejamento do empreendimento. Ela aprova o projeto, sua localização, a viabilidade ambiental, estabelece os critérios e requisitos básicos e as condicionantes que deverão ser atendidas nas fases posteriores do empreendimento;

2) Licença de Instalação (LI) permite a construção da obra, ou seja, a instalação do projeto e engloba as medidas de controle ambiental e as condicionantes;

3) a Licença de Operação (LO) autoriza o funcionamento do empreendimento, no caso de cumprimento das condicionantes das licenças anteriores. Sua validade é estabelecida pelo órgão ambiental licenciador, podendo variar de 4 a 10 anos.

Pedreira, Teixeira e Dupas (2002) apontam que o licenciamento ambiental é de competência dos órgãos ambientais, das esferas federal, estadual e municipal, a saber: Instituto Brasileiro do Meio Ambiente e dos Recursos Naturais Renováveis (IBAMA), os Órgãos Estaduais de Meio Ambiente (OEMA) e os Órgãos Ambientais Municipais, respectivamente.

Ao primeiro cabe a emissão de licenças para empreendimentos e atividades de âmbito nacional ou que afete diretamente o território de dois ou mais Estados; ao segundo compete licenciar empreendimentos e atividades cujos impactos diretos ocorram nos limites territoriais de seus municípios e em unidades de 
conservação estaduais ou em florestas e em áreas de preservação permanente e, por fim, compete aos municípios autorizar empreendimentos e atividades de impacto local e aqueles que lhe forem outorgados a competência pelos Estados.

\section{IMPACTOS DECORRENTES DA IMPLANTAÇÃO DE UHE}

De acordo com Moret e Ferreira (2009), a energia é um fator estruturante da sociedade e o atendimento da demanda por eletricidade no país intervém na economia, na tecnologia, no meio ambiente e em outras esferas, dando causa a uma série de impactos ao meio ambiente. Impacto ambiental é qualquer alteração no sistema físico, químico, biológico, cultural e socioeconômico que possa ser atribuída às atividades humanas (FOGLIATTTI; FILIPPO; GOUDARD, 2004).

A Resolução n ${ }^{\circ} 01$ do CONAMA determina que o licenciamento de obras hidrelétricas com potência acima de 10MW dependerá de EIA-RIMA, que deverão ser submetidos ao órgão licenciador para apreciação. Para tal, a legislação estabelece critérios para análise de implantação de UHE, visto que ao se analisar projetos de construção de UHE, vêm à tona diversos impactos, de caráter positivo ou negativo (FACURI, 2004).

Entre os principais impactos positivos, destacam-se: produção de energia, geração de empregos, menores custos e melhor qualidade da energia elétrica, aumento do potencial de irrigação, aumento do potencial de água potável e de recursos hídricos reservados, criação de possibilidades de recreação e turismo, além da substituição de fontes geradoras de energia mais poluentes, com substituição das termoelétrica (SPERLING, 2012).

Por outro lado, a construção de UHE é uma das ações antrópicas que mais afetam negativamente a natureza e a sociedade, gerando impactos negativos sobre o meio físico, biótico e socioeconômico, tais como comprometimento das atividades econômicas a jusante e à montante da represa devido alteração do regime hidrológico, mudanças na qualidade da água, assoreamento dos corpos hídricos, aumento de doenças de veiculação hídrica, emissão de gases do efeito estufa resultantes da decomposição da vegetação submersa pelo reservatório, perda de espaços de uso público das águas e, sobretudo, a retirada involuntária de populações diretamente afetadas (BERMANN, 2007).

O aumento acelerado da construção de UHE no último século vem alterando os ecossistemas aquáticos e de transição muito mais extensivamente do que qualquer outra atividade antropogênica. Os impactos sobre à ictiofauna são os mais recorrentes, pois após o enchimento do reservatório, as características da água (turbidez, temperatura, concentração de oxigênio) são diretamente afetadas e este é um fator determinante para a alteração no comportamento dos peixes, como predação e reprodução, por exemplo (LEES et al. 2016).

Nas UHE Balbina e Tucuruí, por exemplo, após o enchimento da represa, a água liberada pelas turbinas apresentava-se com baixa concentração de oxigênio dissolvido, causando à mortandade de peixes rio abaixo e dificultando o reestabelecimento da ictiofauna. O bloqueio da migração das populações de peixe também contribui para a redução do estoque pesqueiro nas áreas de influência dessas barragens (FEARNSIDE, 2014).

Outro impacto significativo para a biodiversidade é a perda da vegetação que pode ocorrer, não somente com a inundação do reservatório, mas, como do desmatamento da abertura de estradas e acesso à barragem; também pela população deslocada que desmata as áreas de reassentamento ou outras áreas adjacentes. Soma-se a isso, a presença de populações que migram voluntariamente para essas áreas (FEARNSIDE, 2015). 
Impactos das barragens incluem efeitos sobre populações indígenas que são direta e indiretamente afetadas gerando uma série de conflitos, a exemplo das UHE Belo Monte e Tucuruí, em que a primeira afetou nove terras indígenas, prejudicando mais de 2.200 habitantes e a segunda inundou parte de três áreas indígenas (Parakanã, Pucurui e Montanha) que tiveram seu modo de vida, a manutenção de seus hábitos alimentares, tradições e cultura alterados (FEARNSIDE, 1999; FEARNSIDE 2011; COSTA et. al., 2012).

Pode-se dizer que a construção da UHE de Tucuruí, no estado do Pará, foi um marco no que diz respeito a impactos ambientais e sociais, uma vez que ela submergiu $2.800 \mathrm{~km}^{2}$ de floresta nativa e removeu 4.407 famílias (SOITO; FREITAS, 2011). O fato é que o impacto gerado às populações indígenas é um dos aspectos mais polêmicos de Tucuruí, assim como é o caso para outras barragens existentes e propostas para a Amazônia.

No Brasil, os impactos sociais resultantes da construção e operação de UHE são inúmeros, desde a perda qualidade de vida, decorrente do inchaço populacional de pessoas atraídas pelo empreendimento até o deslocamento e reassentamento de populações nativas, implicando na desestruturação dos laços comunitários e perda de identidade com o território (HAESBAERT, 2007; SPERLING, 2012).

Conflitos socioambientais entre os diversos atores afetados positiva ou negativamente pelas UHE também são comuns. Um conflito bem atual é o do projeto hidrelétrico São Luiz do Tapajós, no rio Tapajós, estado do Pará. Hess e Fenrich (2017) apresentam os complexos conflitos entre atores atingidos pelo projeto da UHE São Luiz do Tapajós, em que as divergências são agravadas, principalmente, pela presença de populações tradicionais (ribeirinhos e povos indígenas). Esses conflitos são resultado de confrontos sobre sistemas produtivos, pois o projeto da UHE não reflete o desenvolvimento endógeno da área.

\section{AS UHE NA AMAZÔNIA}

A região amazônica detém $51 \%$ do potencial hidrelétrico do território nacional, distribuído nas regiões hidrográficas dos rios Amazonas e Tocantins (MME, 2007; MORET'TO et al., 2012). Santos (2015) assinala que os elementos impulsionadores para a expansão energética para a Amazônia são a crescente demanda por energia para abastecer as indústrias do Sudeste do país e as usinas de produção de alumínio e outros metais do Pará, o elevado potencial hidrelétrico não aproveitado da região amazônica somados à saturação do potencial hidrelétrico do Sudeste do país.

Por isso, o Brasil financia e constrói muitas barragens em países vizinhos, a exemplo cita-se a existência de planos para a construção de grandes UHE na Amazônia, com atenção especial para o Brasil, Peru e Bolívia, Colômbia, Suriname, Equador, Venezuela e Guiana. O planejamento prevê duas para a Bolívia, na bacia do rio Madeira, para o Equador estão previstas duas, na encosta oriental da Cordilheira dos Andes, para o Peru seis (início de geração para 2015) (FEARNSIDE, 2014; BERMANN, 2012; FINER e JENKINS, 2012).

O Brasil iniciou um planejamento extensivo para a construção de UHE na Amazônia. Até 2015 o país possuía, já com reservatório preenchido, 15 grandes barragens (potência instalada $>30 \mathrm{MW}$ ) na região. Dentre essas, quatro estão no estado do Amapá, as UHE Coaracy Nunes, Ferreira Gomes, cachoeira Caldeirão e Santo Antônio do Jari, com capacidade instalada inicial de 78 MW e 167 MW, respectivamente (FEARNSIDE, 2016).

Além das mencionadas acima, foram previstas trinta novas UHE grandes para o Brasil até 2020, presentes no Plano Decenal de Expansão Energética 2011-2020 (MME, 2011). Está programada a conclusão 
de 18 dessas UHE, no período de 2012 a 2021 (figura 1) e ainda estão previstas obras para mais 18 UHE amazônicas, segundo o plano decenal 2014-2023 (FEARNSIDE, 2016).

As primeiras UHE da Amazônia planejadas com capital estrangeiro, objetivaram apoiar os projetos de extração de minério, a exemplo das UHE de Coaracy Nunes (Amapá) e Tucuruí (Pará). Coaracy Nunes, localizada no rio Araguari, começou a operar em 1975, para suprir a demanda energética da empresa mineradora de manganês Indústria e Comércio de Minérios S.A (ICOMI) e Tucuruí, no rio Tocantins, foi concebida para abastecer os projetos de produção de alumínio, como o grande Carajás e as indústrias AlbrasAlunorte, e produzir energia para o restante do país (GONÇALVES, 2001; CUNHA, 1999; BERMANN et al., 2010; FEARNSIDE, 2016).

Figura 1 - UHE em construção e planejadas - Amazônia brasileira - 2012 a 2021

\begin{tabular}{|c|c|c|c|c|c|}
\hline Nome & Rio & Estado & Capacidade instalada (MW) & Ano construção & Status \\
\hline Santo Antônio & Madeira & Rondônia & 3150 & 2012 & Reservatório preenchido \\
\hline Jirau & Madeira & Rondônia & 3750 & 2013 & Reservatório preenchido \\
\hline Santo Antônio do Jari & Jari & Pará/Amapá & 370 & 2014 & Reservatório preenchido \\
\hline Belo Monte & Xingú & Pará & 11.233 & 2015 & Em construção \\
\hline Colíder & Teles Pires & Mato Grosso & 300 & 2015 & Reservatório preenchido \\
\hline Ferreira Gomes & Araguari & Amapá & 252 & 2015 & Reservatório preenchido \\
\hline Teles Pires & Teles Pires & Mato Grosso & 1.819 & 2015 & Reservatório preenchido \\
\hline Sinop & Teles Pires & Mato Grosso & 400 & 2018 & Em construção \\
\hline Cachoeira Caldeirão & Araguari & Amapá & 219 & 2017 & Planejado \\
\hline São Manoel & Teles Pires & Mato Grosso & 700 & 2017 & Planejado \\
\hline Ribero Gonçalves & Parnaíba & Maranhão/Piauí & 113 & 2018 & Planejado \\
\hline São Luiz do Tapajós & Tapajós & Pará & 8.040 & 2020 & Planejado \\
\hline Jatobá & Tapajós & Pará & 2.338 & 2021 & Planejado \\
\hline Água Limpa & Das Mortes & Mato Grosso & 320 & 2020 & Planejado \\
\hline Bem Querer & Rio Branco & Roraima & 708 & 2022 & Planejado \\
\hline Simão Alba & Juruena & Mato Grosso & 3.509 & 2021 & Planejado \\
\hline Marabá & Tovantins & Pará & 2.160 & 2021 & Planejado \\
\hline Salto Augusto Baixo & Juruena & Mato Grosso & 1.464 & 2021 & Planejado \\
\hline
\end{tabular}

Fonte: Adaptado de Fearnside (2016).

\section{HISTÓRICO DA UHE SANTO ANTÔNIO DO JARI}

A UHE Santo Antônio do Jari aproveita a queda natural do rio Jari onde se formam cachoeiras com cerca de 10 m de altura. Operando a fio d'água gera atualmente 373 MW de potência instalada. Está localizada entre os municípios de Laranjal do Jari/AP e Almeirim/PA, a $150 \mathrm{~km}$ da foz do rio Jari (CESBE, 2018).

O seu licenciamento passou várias etapas, incluindo o cancelamento do processo de licenciamento ambiental, iniciado em 1987, por decurso de prazo, conforme especificado na resolução CONAMA 237/97. A retomada do processo de licenciamento junto ao IBAMA ocorreu em 2008 culminando com a concessão da licença de operação, em 2014. A linha do tempo a seguir ajuda a compreender o histórico do empreendimento e de seu licenciamento ambiental.

Os primeiros estudos para a investigação de viabilidade hidrelétrica na bacia do rio Jari, ocorreram 
durante a implantação do Projeto Jari entre 1973 e 1986, que constataram a existência de potencial hidrelétrico economicamente aproveitável da Cachoeira de Santo Antônio (ECOLOGY BRASIL, 2009b).

Após averiguado esse potencial, em 1987, foi permitida a concessão para a UHE Santo Antônio do Jari, com duas unidades geradoras e capacidade de produção de 68 MW. Os primeiros estudos ambientais são apresentados no Projeto Básico Ambiental (PBA) identificaram a necessidade de reassentamento das comunidades Santo Antônio da Cachoeira e São Francisco do Iratapuru, presentes na área diretamente afetada pelo empreendimento (CAMPOS; PORTO; CAMPOS, 2017).

Em 1989, o IBAMA concede à empresa Jari Energética S.A, a LI nº 001/1989, da UHE Santo Antônio do Jari, que posteriormente foi renovada/prorrogada em 1990, 1991, 1993, 1996 e 2000. É importante destacar que após a emissão das LI os moradores das áreas diretamente afetadas se organizam e elegem um representante para acompanhar e negociar com a empresa responsável, o local destinado ao reassentamento (ECOLOGY BRASIL, 2009c). Porém, essa licença foi cancelada por decurso de prazo, como mencionado anteriormente.

Em 1995, intensificam-se as reuniões comunitárias, que culminaram na assinatura do Protocolo de Entendimento firmado entre a Jari Energética, as comunidades (Santo Antônio da Cachoeira, Santo Francisco do Iratapuru e Padaria), o Governo do Estado do Amapá, a Prefeitura e a Câmara Municipal de Laranjal do Jari.

Nesse documento a empresa se compromete com as comunidades afetadas e prevê a construção da nova vila para os moradores de Santo Antônio da Cachoeira, estruturadas com energia elétrica, posto médico, saneamento básico (captação de água, tratamento, fossas individuais), indenização de benfeitorias e plantios atingidos, construção de trapiche e um atracadouro para embarcações no Porto Sabão, dentre outros. Após cinco anos da assinatura do protocolo de entendimento é construída a vila Santo Antônio da Cachoeira, no prolongamento do antigo lugar de mesmo nome e realizada a mudança da população para a área nova.

No biênio 2004-2005, a Agência Nacional de Energia Elétrica (ANEEL) aprova a revisão do PBA da UHE Santo Antônio do Jari, com capacidade de produção aumentada de 100 para 167 MW de potência instalada e o IBAMA determina a realização de novos estudos ambientais e elaboração do EIA para a expedição de nova LI. Três anos mais tarde, diante da previsão de interligação de Macapá ao Sistema Interligado Nacional (SIN), presente no Plano Decenal de Expansão de Energia Elétrica 2006-2015, a ANEEL determina que a revisão do projeto básico do aproveitamento, para a inclusão de melhorias no sistema a fim de subsidiar a interligação ao SIN (MME, 2007; ECOLOGY BRASIL, 2009b; CAMPOS, 2016).

\section{ESTUDOS AMBIENTAIS DO LICENCIAMENTO}

Em julho de 2008, o IBAMA emite novo termo de referência com as diretrizes para os EIA visando a retomada do licenciamento ambiental da UHE Santo Antônio do Jari. Essa retomada se deu a partir da reformulação da concepção original do projeto, que além de alterar sua capacidade de geração, também modificou a localização da casa de força e do canteiro de obras, as quais possibilitaram preservar Cachoeira de Santo Antônio e evitaram a criação de novos acessos e ocupação desordenada na margem esquerda do rio Jari, tornando o projeto mais satisfatório sob a ótica ambiental e social (ECOLOGY BRASIL, 2009a). O novo processo de licenciamento ambiental de Santo Antônio do Jari apresentou as seguintes etapas (figura 2). 
Figura 2 - Etapas do licenciamento da UHE Santo Antônio do Jari

\begin{tabular}{|l|l|}
\hline ETAPA & DATA \\
\hline Licença Prévia $n^{\circ} 337$ & 08 de dezembro de 2009 \\
\hline Licença de Instalação n 798 & 03 de junho de 2011 \\
\hline Licença de Operação $n^{\circ} 1233$ & 03 de maio de 2014 \\
\hline
\end{tabular}

Fonte: www.ibama.gov/licenciamento.

O Parecer Técnico no 120/2009 do IBAMA, após análise dos aspectos envolvidos no EIA e os subsídios decorrentes de vistorias, reuniões técnicas e audiências públicas, concluiu pela viabilidade ambiental do empreendimento. Após esse parecer o IBAMA concede a LP no 337/2009, desde que atendidas as 25 condicionantes referentes aos programas de indenização e remanejamento, à conservação e monitoramento de fauna e flora, qualidade da água, recuperação de áreas degradadas, supressão de vegetação e limpeza do reservatório, dentre outros (IBAMA, 2009).

Cabe aqui registrar que, embora seja favorável à emissão da LI, o parecer supracitado reforça que empreendedor deve dar atenção especial às áreas de influência direta e indireta, pois são regiões com problemas sociais permanentes, com possibilidade de agravamento com o aumento do fluxo migratório, ligado à massa operária atraída pelas obras da UHE.

O documento destaca, ainda, que os programas ambientais não contemplam todas as esferas da vida socioeconômica afetadas, recomendando o reforço dos programas de cunho social e a inclusão de outros programas relacionados ao controle e monitoramento de migração, apoio à habitação, segurança e educação, capacitação dos agentes públicos e de mão de obra local e programa de indenização e remanejamento da população afetada.

O Parecer Técnico no 44/2011, acusou o descumprimento e o cumprimento parcial de algumas condicionantes. Pendências relativas à manifestação favorável do Instituto do Patrimônio Histórico e Artístico Nacional (IPHAN) ao início das obras e à assinatura de termo de compromisso para a implantação do Plano de Compensação Ambiental no valor de R \$ 3.697.919,99, foram encontradas.

Feitas as considerações, foi recomendando que a LI fosse concedida somente se as pendências fossem sanadas, mesmo sem o cumprimento de todas as condicionantes, a LI n 798/2011 foi concedida em junho de 2011 (IBAMA, 2011). A LO n 1233/2014 foi emitida em maio de 2014. Em face disso, a ANEEL autoriza a primeira unidade geradora da UHE Santo Antônio do Jari operar comercialmente, em setembro de 2014 (IBAMA, 2011; EXAME, 2014).

Em 2013, o Ministério Público Federal do Pará (MPF/PA) entrou com uma ação civil pública, contra o IBAMA e a empresa responsável pela UHE, solicitando a anulação das LP e da LI por irregularidades. De acordo com o MPF/PA, o EIA-RIMA estão incompletos e, além disso, o empreendedor não teria cumprido as condicionantes da LP, dessa forma teria sido irregular a emissão da LI.

Ainda segundo a ação, a ausência de diagnósticos importantes nos EIA compromete a participação popular e a manifestação do cidadão no processo de licenciamento ambiental (MPF/PA, 2013). Em 2015 o juiz Federal, Arthur Pinheiro Chaves, julgou improcedente o pedido do MPF/PA por considerar não haver prejuízo para a participação popular, advindo da forma como foi conduzido o licenciamento (BRASIL, 2015). 


\section{IMPACTOS SOCIOAMBIENTAIS DA UHE SANTO ANTÔNIO DO JARI}

A instalação da UHE de Santo Antônio do Jari suscitou muitos impactos sobre a região, de caráter positivo e negativo. Os principais impactos positivos são: aumento da massa salarial, arrecadação de impostos e aumento da oferta de energia. Entretanto, os impactos negativos são os mais perceptíveis, tais como a indução a processos erosivos, alteração da qualidade da água e dos ecossistemas terrestres e aquáticos (incluindo impactos sobre a pesca), aumento de incidência de doenças (sexualmente transmissíveis e arboviroses), alteração da paisagem natural, sobrecarga da infraestrutura dos municípios, desestruturação dos laços comunitários, perda da qualidade de vida das comunidades e perdas de áreas de moradias e produção (ECOLOGY BRASIL, 2009b).

Considerando os impactos acima mencionados, o PBA da Santo Antônio do Jari previu a execução de 38 programas de natureza ambiental e social para mitigá-los. Os programas abordam os seguintes temas: recuperação de áreas degradadas, monitoramento de processos erosivos, saúde, segurança, controle da poluição, conservação de flora e fauna, educação ambiental, indenização e remanejamento da população afetada, capacitação dos moradores locais, controle e monitoramento do processo migratório, fomento às atividades pesqueira e extrativista, fornecimento de mecanismos de educação patrimonial e preservação histórica do lugar (CAMPOS; PORTO; CAMPOS, 2017; ECOLOGY BRASIL, 2009a,b).

Entretanto, as ações mitigatórias se revelaram frágeis pois não consideraram os recortes geográficos, a situação climática, as limitações do sistema de transporte e a utilização da mão de obra local, resultando no aparecimento de novos problemas, diferentes daqueles presentes na vida cotidiana das comunidades (CAMPOS, 2016).

As comunidades Santo Antônio da Cachoeira, São Francisco do Iratapuru, São José e Padaria, além de algumas moradias ribeirinhas, presentes na área de formação do reservatório, sofreram influência direta da implantação da UHE. Os moradores de Santo Antônio tiveram suas casas reconstruídas, em área adjacente à anterior, num processo iniciado em 1995 e concluído em dezembro de 2001.

Ao todo foram construídas vinte novas casas, uma escola, um posto de saúde e um centro comunitário. Apesar disso, os moradores têm enfrentado problemas relacionados ao processo de assentamento, tais como ocupação multifamiliar em casas com dimensões planejadas para apenas uma família; casas construídas em terreno inadequado, resultando em instabilidade e na mudança no local de algumas dessas moradias (ECOLOGY BRASIL, 2009 a,c).

A população da comunidade de São Francisco do Iratapuru foi reassentada com atraso de três anos, em 2014, em local relativamente distante do rio. O programa de reassentamento, após intensa negociação com a Secretaria de Estado do Meio Ambiente, entregou 34 novas casas com arruamento, eletrificação solar e gerador tradicional, rede de saneamento básico e de iluminação pública, ampliação da escola, quadra poliesportiva, posto médico e policial, atracadouro para embarcações, dentre outros.

Porém, pouco tempo da entrega muitos problemas foram surgindo, especialmente nas redes: de água tratada, de saneamento básico e de energia elétrica, que não funcionam adequadamente e, portanto, não suprem a necessidade da população (TOLEDO, 2016; CAMPOS; PORTO; CAMPOS, 2017).

Campos (2016) destaca que São Francisco do Iratapuru também teve suas atividades econômicas impactadas. Com a alteração do nível do rio, lavouras de subsistência e castanhais próximos foram inundados e, por isso, os castanheiros tiveram que se deslocar para regiões mais distantes, aumentando o esforço físico e financeiro para acessar e transportar a produção de castanha da amazônia, o que de certa forma 
contribuiu para uma baixa produtividade no período de 2014 e 2015. Da mesma forma, sofreram moradores de Santo Antônio da Cachoeira e Padaria.

A Cooperativa Mista dos Produtores e Extrativistas do rio Iratapuru (COMARU) teve sérios transtornos, pois adquiriu maquinário para beneficiamento da castanha e ficou impossibilitada de usá-lo, porque a geração de energia elétrica 24 horas, medida compensatória da implantação da UHE, não ocorreu. Em decorrência disso, ela tem arcado com óleo diesel para gerar eletricidade via motor e vem tendo prejuízos econômicos que resultaram na diminuição dos lucros e da renda familiar dos cooperados (CAMPOS; PORTO, CAMPOS, 2017).

Para Bermann (2007) e Souza (2010), o remanejamento compulsório dos moradores representa modificações nas suas relações com os recursos naturais, no seu modo de vida e nas redes de sociabilidade dos grupos sociais. Embora a ligação dessas pessoas com o meio ambiente seja de natureza cultural, econômica e social, em muitos casos esses aspectos sequer são mencionados como relevantes nos EIA, sendo muito comum que populações ribeirinhas sejam desconsideradas diante da perspectiva da perda irremediável das suas condições de produção e reprodução social, determinada pela instalação do reservatório.

\section{CONSIDERAÇÕES FINAIS}

O licenciamento ambiental de uma UHE requer que as legislações ambientais sejam consideradas desde as etapas iniciais de concepção dos projetos, para que se possa tentar a busca ao equilíbrio entre os elementos de natureza econômica, política, ambiental e técnica, já que o modelo utilizado para a instalação de UHE coloca como prioritários os interesses econômicos em detrimento dos socioambientais. Assim, o licenciamento ambiental, alicerçado no direito ambiental, deve sempre cumprir seu papel de conciliar o desenvolvimento econômico com a conservação do meio ambiente.

Considerando o resgate histórico da UHE Santo Antônio, pode-se depreender que Santo Antônio do Jari se configura como um empreendimento de profundo interesse social e de utilidade pública, na medida em que a energia gerada por ela contribui para a redução da participação térmica na matriz energética do país. Embora os impactos proporcionados por sua construção sejam de grande relevância, implicaram em transformações socioambientais profundas nas áreas direta e indiretamente afetadas.

A reconstrução das vilas de Santo Antônio da Cachoeira e São Francisco do Iratapuru, um dos principais efeitos decorrentes da implantação da UHE, culminou em mudanças profundas na relação das comunidades com o meio ambiente. Essas mudanças estão relacionadas à perda da relação cultural que possuíam o ambiente, a perdas das áreas de produção agrícola, de extrativismo e de sítios de pesca, que afetaram drasticamente a forma de utilização do território, pautada no uso racional dos recursos ambientais.

\section{REFERÊNCIAS}

BANCO MUNDIAL. Licenciamento Ambiental de Empreendimento Hidrelétricos no Brasil: Uma Contribuição para o Debate - volume I: Relatório Síntese. Brasília, 2008. 34p.

BERMANN, C. Impasses e controvérsias da hidreletricidade. Estudos Avançados, v. 21, n. 59, p. 139-153, 2007.

C. O projeto da Usina Hidrelétrica Belo Monte: a autocracia energética como paradigma. Novos Cadernos NAEA, v. 15, n. 1, p. 5-23, 2012. 
BERMANN, C.; WITTMANN, D.; HERNÁNDEZ, F. D. M.; RODRIGUES, L. A. Usinashidrelétricas na Amazônia - o futuro sob as águas. Seminário Políticas públicas e obras de infra-estrutura na Amazônia: Cenários e desafios para o fortalecimento da governança socioambiental, Brasília, 2010.

BRASIL. Lei $n^{\circ}$ 6.938, de 31 de agosto de 1981. Dispõe sobre a Política Nacional do Meio Ambiente, seus fins e mecanismos de formulação e aplicação, e dá outras providências. Brasília, DF, 1981.

Decreto $n^{\circ}$ 99.274, de 06 de junho de 1990. Regulamenta a Lei n 6.902, de 27 de abril de 1981, e a Lei $n^{\circ} 6.938$, de 31 de agosto de 1981, que dispõem, respectivamente sobre a criação de Estações Ecológicas e Áreas de Proteção Ambiental e sobre a Política Nacional do Meio Ambiente, e dá outras. Brasília, DF, 1990. Publica no DOU em 07.06.1990

Tribunal Regional Federal da Primeira Região. Ação Civil Pública Ambiental sob processo no 5244-25.2013.4.01.3900. Sentença considerando improcedente, do Juiz Arthur Pinheiro Chaves, 2015. Disponível em: <http://processual.trf1.jus.br/consultaProcessual/processo.php?\&secao $=$ PA\&proc $=00052442520134013900>$. Acesso em: 20 jan. 2018.

CAMPOS, K.F.S. Novas dinâmicas territoriais da Usina Hidrelétrica de Santo Antônio no vale do Jari: a desconstrução do uso do território e de produtos na RDS do Iratapuru/AP. 2016. 108p. Dissertação (Mestrado Desenvolvimento Regional) - Universidade Federal do Amapá, Macapá, 2016.

CAMPOS, K.F.S.; PORTO, J.L.R.; CAMPOS, V.B. Hidrelétrica no sul do estado do Amapá: impactos sociais na Vila de São Francisco - RDS do Iratapuru. In: SILVA, C.N.; LIMA, R.A.P.; SILVA, J.M.P. (Org.). Território, ordenamentos e representações na Amazônia. 1. ed. Belém: GAPTA/UFPA, 2017. p. 109137.

CESBE. CESBE S.A. ENGENHARIA E EMPREENDIMENTOS. Disponível em: <http://www.cesbe.com. br/obras/uhe-santo-antonio-do-jari/> Acesso: 20 fev. 2018.

CONAMA - Conselho Nacional do Meio Ambiente. Resolução Conama $n^{\circ} 01$, de 23 de janeiro de 1986. Disponível em: <http://www.mma.gov.br/port/conama/res/res86/res0186.html. Acesso em: 09 jan. 2018.

Resolução Conama n²37, de 19 de dezembro de 1997. Disponivel em: < http://www.icmbio.gov.br/cecav/images/download/CONAMA\%20237_191297.pdf. Acesso em: 09 jan. 2018.

COSTA, B. B. S.; SANTOS, G.O.S.; MENEZES, A.C.; OLIVEIRA, I.F.S.; MELO, I.C.; SANTOS, W.L.; MEDEIROS, S.L. Licenciamento ambiental no Brasil sobre usinas hidrelétricas: um estudo de caso da usina de Belo Monte, no Rio Xingu (PA). Cadernos de graduação, ciências exatas e tecnológicas, v. 1, n. 15, p. 19-33, 2012.

CUNHA, H. F. A. Avaliação da eficácia de medida mitigadora de impactos socioambientais causados por construção de hidrelétricas: o reassentamento populacional da UHE de Taquaruçu - SP. 1999. 169 p. Tese (Doutorado em Engenharia Ambiental) -Universidade de São Paulo, São Carlos, 1999.

ECOLOGY BRASIL. UHE Santo Antônio Jari: Plano Básico Ambiental - PBA, Rio de Janeiro, $2009 a$.

. UHE Santo Antônio Jari: Estudo de Impacto Ambiental - EIA. Rio de Janeiro, 2009b.

UHE Santo Antônio Jari: Relatório de Impacto Ambiental - RIMA. Rio de Janeiro, 2009c.

EXAME. Aneel autoriza operação de turbina da hidrelétrica no Jari. 2014. Disponível em: <https://exame.abril.com.br/brasil/aneel-autoriza-operacao-de-turbina-da-hidreletrica-no-jari/>; Acesso em 23 jan 18.

FACURI, M. F. A implantação de usinas hidrelétricas e o processo de licenciamento ambiental: A importância da articulação entre os setores elétricos e de meio ambiente no Brasil. 2004. 88 p. 
Dissertação (Mestrado em Engenharia da Energia) - Universidade Federal de Itajubá, Itajubá, 2004. FEARNSIDE, P.M. Social impacts of Brazil's Tucuruí Dam. Environmental Management, v. 24, n. 4, p. 483-495, 1999. Doi: 10.1007/s002679900248

, P.M. Usina Hidrelétrica de Belo Monte em pauta. Política Ambiental, n 7, jan. 2011. Disponível em: //philip.inpa.gov.br/publ_livres/2011/Belo\%20Monte-oliica\%20Ambiental\%20. 2011. pdf. Acesso em: 07 de jan. 2018

, P.M. Análisis de los principales proyectos hidroenergéticos en la región amazónica. Derecho, Ambiente y Recursos Naturales (DAR) \& Centro Latinoamericano de Ecología Social (CLAES), Lima, Peru. 2014 55p. Disponivel em: http://www.dar.org.pe/archivos/publicacion/147_Proyecto_hidro-energeticos.pdf.

, P.M. Hidrelétricas na Amazônia: impactos ambientais e sociais na tomada de decisões sobre grandes obras. Manaus: Editora do INPA. 2015. 296 p.

, P.M. Environmental and social impacts of hydroelectric dams in Brazilian Amazonia: implications for the aluminium industry. World Development, v. 77, p. 48-65, 2016.

FINER, M.; JENKINS, C. N. Proliferation of Hydroelectric Dams in the Andean Amazon and Implications for Andes-Amazon Connectivity. Plos One, v. 7, n. 4, 2012.

FOGLIATTI, M. C.; FILIPPO, S.; GOUDARD, B. Avaliação de impactos ambientais: aplicação aos sistemas de transporte. Rio de Janeiro: Interciência. 2004. 250 p.

GONÇALVES, C.W.P. Amazônia, Amazônias. São Paulo: Contexto. 2001. 178 p.

HAESBAERT, R. Território e multiterritorialidade: um debate. GEOgraphia, v. 9, n.19, p. 19-45, 2007.

HESS, C.E.E.; FENRICH, E. Socio-environmental conflicts on hydropower: the São Luiz do Tapajós project in Brazil. Environmental Science and Policy, v.73, p. 20-28, 2017.

IBAMA. Instituto Brasileiro do Meio Ambiente e dos Recursos Naturais Renováveis. Análise técnica do EIA/RIMA e de documentos correlatos referentes à UHE de Santo Antônio do Jari, visando emissão de parecer quanto à viabilidade ambiental do empreendimento. Parecer técnico $n^{\circ} 120$, de 08 de dezembro de 2009. Relatores: Alexandre Romariz Duarte, Carlos Henrique Cardoso, Fabíola Schupcheki Cleto, Luiz Fernando Suffiati, Marcos Fernando de Assis. Licenciamento Ambiental do Ibama. 2018.

. Análise do atendimento às condicionantes Licença Prévia no 337/2009 e da adequação dos Programas Básicos Ambientais (PBAs) propostos para o AHE Santo Antônio do Jari. Parecer técnico $n^{\circ}$ 44, de 06 de maio de 2011. Relatores: sem nomes. Licenciamento Ambiental do lbama. 2018. IBAMA. Licenciamento Ambiental. 2018. Disponível em: <https:// https://servicos.ibama. gov.br/licenciamento/consulta_empreendimentos.php>; Acesso em 10 jan 18.

LEES, A. C.; PERES, C. A.; FEARNSIDE, P. M.; SCHNEIDER, M.; ZUANON, J. A. S. Hydropower and the future of Amazonian biodiversity. Biodiversity and Conservation, v. 25, p. 451-466, 2016.

MME - MINISTÉRIO DE MINAS E ENERGIA. Secretaria de Planejamento e Desenvolvimento Energético; Empresa de Pesquisa Energética - EPE. Plano Nacional de Energia 2030. Brasília: MME; EPE, 2007.

Secretaria de Planejamento e Desenvolvimento Energético; Empresa de Pesquisa Energética - EPE. Plano Decenal de Expansão de Energia 2020. Brasília: MME; EPE, 2011. 
. Secretaria de Planejamento e Desenvolvimento Energético; Empresa de Pesquisa Energética - EPE. Plano Decenal de Expansão de Energia 2021. Brasília: MME; EPE, 2012.

MORET, A.S.; FERREIRA, I.A. As hidrelétricas do rio Madeira e os impactos socioambientais da eletrificação no Brasil. Ciência Hoje, v.45, n. 265, p 46-52, 2009.

MORETTO, E. M.; GOMES, C. S.; ROQUETTI, D. R.; JORDÃO, C. O. Histórico, tendências e perspectivas no planejamento espacial de usinas hidrelétricas brasileiras: a antiga e atual fronteira amazônica. Revista Ambiente \& Sociedade, v. 15, n. 3, p. 141-164, 2012.

MPF - MINISTÉRIO PÚBLICO FEDERAL. Acusados de irregularidades em licença da hidrelétrica de Santo Antônio do Jari (PA) são notificados. 2013. Disponível em: <http://www.mpf.mp.br/pa/salade-imprensa/noticias-pa/justica-notifica-acusados-de-irregularidades-em-licenca-ambiental-da-hidreletrica-de-santo-antonio-do-jari. Acesso em 23 jan 18.

PEDREIRA, A., TEIXEIRA, D. R; DUPAS, F. A. 0 processo de licenciamento ambiental para implantação de empreendimentos de pequenas centrais hidrelétricas - aspectos legais e institucionais. Poços de Caldas, 2002.

PIAGENTINI, P.M.; BENASSI, R.F; PENTEADO, C.L.C. Olhares sobre a hidreletricidade e o processo de licenciamento no Brasil. Estudos Avançados, v. 28, n. 82, p. 139-153, 2014.

SANTOS, E.S. Usina Hidrelétrica Ferreira Gomes e impactos socioeconômicos aos pescadores antes e depois do enchimento do reservatório. 2015. 166 p. Dissertação (Mestrado em Direito Ambiental e Políticas Públicas) - Universidade Federal do Amapá, Macapá, 2015.

SOITO, J. L. S.; FREITAS, M. A. V. Amazon and the expansion of hydropower in Brazil: Vulnerability, impacts and possibilities for adaptation to global climate change. Renewable and Sustainable Energy Reviews, v. 15, p. 3165-3177, 2011.

SOUZA, J. C. Um ensaio sobre a problemática dos deslocados ambientais: a perspectiva legal, social e econômica. Veredas do Direito, v. 7, n.13/14, p.57-73, 2010.

SPERLING, E. V. Hydropower in Brazil: overview of positive and negative environmental aspects. Energy Procedia, v. 18, p. 110-118, 2012.

TOLEDO, G.T. A regulação do acesso aos conhecimentos tradicionais associados a recursos genéticos no Brasil: a experiência do Amapá. 2016. 170 p. Dissertação (Mestrado em Uso e Aproveitamento de recursos Naturais: pesquisa e desenvolvimento de recursos naturais) - Universidade Federal do Pará, Belém, 2016.

TCU - Tribunal de Contas da União. Cartilha de licenciamento ambiental. 2a Edição: Brasília, 2007 